Biannual Research Journal Grassroots

Vol.55, No.I, 2021: 95-113

Grassroots

\title{
AN EXISTENTIAL ANTHROPOLOGICAL STUDY OF SELFHOOD, UNCERTAINTY AND RESILIENCE AMONG YOUTH OF TANDO GHULAM ALI, SINDH
}

\author{
Ali Taqui Shah \\ Lecturer, Department of Anthropology \& Archeology, University of Sindh \\ Email: alitaqui.shah@usindh.edu.pk \\ Abdul Razaque Channa-Ph.D. \\ Postdoctoral Fellow at the Lakshmi Mittal and Family South Asia Institute \\ Harvard University Email: achanna@fas.harvard.edu \\ Assistant Professor at the Department of Anthropology and Archaeology \\ University of Sindh, Jamshoro \\ Email: razaque.channa@usindh.edu.pk \\ Syed Faisal Hyder Shah \\ Assistant Professor, Department of Social Work, University of Sindh, Jamshoro \\ Email: faisal.shah@usindh.edu.pk
}

\begin{abstract}
This study combines three orientations, namely existential thought about the meaning of 'being' and 'existence,' phenomenological insights into 'lived experience,' and anthropological endeavor at what it means to be human. It attempts to focus on the human conditions by directly engaging with human beings. Specifically guiding itself with the questions such as how young people engage in the meaning-making of their lived experiences in their life course's ever-changing process. Taking its theoretical insights and inspiration from existential and phenomenological anthropology, by zooming in on lived experiences, the research was conducted using life story interviews to collect the narratives to gain understandings into the life-worlds as it is lived and made sense of by young people of Tando Ghulam Ali, a rural town of District Badin, Sindh. Based on the ethnographic data and observations, it is argued that the meaning-making of lived experiences was different among research participants with a strong presence of selfhood and self-consciousness temporally and affectively; the difference in orientation towards life is entangled with personal history as well. This research went beyond the horizons of culture and society to put existence, life, and being, which are silhouetted at meta-level, at the heart of anthropological focus. This research is an experimental research project in anthropology, which has attempted to step its foot into the human condition's terra incognita, which calls for anthropologists' further exploration.
\end{abstract}

Keywords: Culture, Existential Anthropology, Individual, Anthropological theory 


\section{INTRODUCTION}

Of late, social sciences and anthropology have witnessed transformative changes in their outlook and practices; one can see that by looking at the number of 'turns' social sciences have been introduced to. For instance, there is 'ontological turn', 'affective turn', 'narrative turn', 'existential turn' and so on, which have enormously affected the very foundations of social sciences. However, in this paper, we intend to solely focus on the existential orientation called 'Existential anthropology' (Jackson \& Piette, 2015). Although one of the most influential proponents of existential anthropology, Michael Jackson (2013) thinks that scholars do not need to trace existential anthropology's roots in philosophy. However, we believe it is indispensable to sketch and discuss some of the significant issues, themes, and existentialist philosophical ideas. We will explore and elucidate the theory and methodology of Existential anthropology and its fundamental objectives to the research in the domain of anthropology. Inspired by the classical social scientific paradigm of Durkheim, Malinowski, and Marx, social science research has been unduly based on either community studies, state formation, or civilmilitary issues in Pakistan as well as Sindh. There is minimal research that focuses on inter subjectivity, selfhood, and interrelationship of culture and individual agency (Leys, 1976; Siddiqa \& Siddiqa-Agha, 2007; Rahman, 2012).

This research employed existential and phenomenological concepts such as lived experience, existence, meaning-making, selfhood, uncertainty, and resilience in a single individual as a point of departure (Hahn, 2012; Desjarlais \& Throop, 2011). This research focuses on understanding the self-conception among Tando Ghulam Ali's youth, at own situated in district Badin, which lies in the rural part of Pakistan's Sindh province. Since the research is based on phenomenological method of 'bracketing' the traditional technique of seeing individuals as a byproduct of the community was intentionally avoided. Instead, they were understood to be in the dynamic relationship of their life world with the world of others.

\section{LITERATURE REVIEW}

Existence and Existence-Philosophy: Like existentialist philosophy, existential anthropology puts the problem of existence back at the heart of any understanding of human beings. The ideas and approaches about human beings are strongly challenged in support of an existentially sensitive perspective that is finely attuned with human 
life complexities. It carefully addresses the precariousness of being and its complicated relationship to the world it shares with others. According to existentialist philosopher Merleau-Ponty (1962), the aim is "to return to that world which precedes knowledge, of which knowledge always speaks, and in relation to which every scientific schematization is an abstract and derivative sign-language, as is geography in relation to the country-side in which we have learnt beforehand what a forest, a prairie or a river is" (as cited in Wrathall, 2006:31-47). Existentialist philosophy also contests the priority of epistemology over ontology and argues that human beings cannot be understood with formulaic thinking and reasoning alone; more importantly, the scientific abstraction through which they are categorized into groups, sexes, classes tend to overlook the fundamental problems of existence and a host of issues that stem from it. For example, Jaspers (1970) argues against the possibility of grasping existence on a rational basis and thinks that it is not accessible to one who tries to understand it by being objective. Any opportunity arises only when one goes beyond the limitations of objectivity and rationality. Heidegger (1962) considers the concept of existence as a precondition to grasp the essence of human being, "Its being-what-it-is (essential) must, so far as we can speak of it at all, be conceived in terms of its being (existentia)" (as cited in Teitz, 2006:166).

Additionally, the overemphasis on human being's rational capacities is also criticized, stating that although we are entitled with the thinking and reasoning faculties, this is just a one-dimensional picture of it, since we are bestowed with emotions and passions as well; we have feelings of desires, hopes, disappointments, love, hatred, happiness, sadness, empathy and jealousy. As Heidegger (1962) points out that 'Dasein finds 'itself' first of all in what it pursues, needs expects, prevents - in what is environmentally available, which first of all concerns it" (as cited in Wrathall, 2006:39). By elucidating and uncovering the oft-ignored facets of human existence, existencephilosophy is also highly critical of subject-object dualism. Being is always being-in-the-world, what is more, and the wholesale dismissal of the concept of 'subject' in the natural and social sciences.

Existential analytic or Analytic of Dasein: Heidegger considers the being as problematic in itself and thinks that it is the fundamental 
question of philosophy to address it, however, as he contends that all of the questions pertaining to being have been related to the ontic concerns, such as this or that exists or why it exists, because the being is never being problematized on the ontological frame of reference. This is where he develops the field of analytic of Dasein, the specialized field of research, which will dedicate itself to the question of the meaning of being vis-à-vis positivist philosophy, which has always tended to take being for granted in a vein to looking for "what questions" (Teitz, 2006). In the same fashion, anthropologist James F. Weiner (2001) who advocates Heideggerian anthropology, also questions anthropologists assumptions about the nature of human beings and their mode of engagement with the world with terms like society, community and culture. He holds that although anthropologists dedicate themselves to the analysis of cultural differences, they make such assumptions that result in harsh generalizations "....for example, that our behavior is rule ordered; that social relations are unequal; that productive relations determine other kinds of relations - that themselves conceal a host of questions about the nature of 'a rule', 'social relations,' and 'production'." (Weiner, 2001:3)

What is Existential Anthropology?: Existential anthropologist's point of departure is an individual. According to them, an individual is not a replica of so-called culture or society, which can be used just as an instance to prove some intellectual point. As an existential entity, not merely coping and adjusting oneself in his world but also equipped with creating and acting over the world's forces that hold sway on him. Therefore, Albert Piette (2014) thinks that the "idea of existence would provide a foundation for anthropology and re-justify it (p.231)".

This focus on single individual calls for a shift, Albert Piette (2014) argues, from traditional anthropology whose main concerns have been, thanks to a certain epistemological attitude, 'social' and 'cultural,' in which they strive to prove that how individuals comply with the social conventions and norms and how neatly they fit into that whole which is called culture. For instance, among others, the experiential characteristic of experiencing moods, which although other life forms too have, such as boredom and absurdity, can make human beings more aware of their 'thrownness' in the world and tempt 
them to turn upside down all of the sense of belongingness with themselves and their world (Piette, 2014).

\section{The Life Story: Definition, Historical Roots, And Its Practice Defining Life Story}

According to the renowned life story researcher Robert Atkinson (2002), "A life story is a story of a person chooses to talk about the life he or she has lived, told as completely and honestly as possible, what the person remembers of it and what he or she wants others to know of it, usually as a result of a guided interview by another (p.125)". However, we agree with the views of Bertaux and Kohli (2008) that although life history is mainly understood to be just another method of data collection, the researchers in the field have used it briefly to addresses some of the core epistemological issues and theoretical questions. While Robert Atkinson (2002) argues that a life story interview is not a new interest or completely new phenomenon, quite contrary, this interview technique took its modern form through oral history, life history, ethnography, and other qualitative field techniques. "Life story interviewing is a qualitative research method for gathering information on the subjective essence of one person's entire life that is transferable across disciplines (pp.122-123)". When it comes to the difference between life history and life story, generally, there is no distinction made between the two as Bertaux and Kohli (2008) note. "Both of these sources (life history and life story)give the researcher access to the actor's perspective: his or her values, definitions of situations, and knowledge of social processes and rules that he or she has acquired through experience... it is appropriate to insist on a more specific characterization: the life story approach should be based on narratives about one's life or relevant parts thereof (p.43)"'.

There is a common perception that life story work indulges itself too much in individualism and ignores objectivity. However, it should be noted that many of the researchers in the field have had quite diverse backgrounds, plans, interests and theoretical orientations who have explored their particular research problems and questions by utilizing this method in the field (Bertaux \& Kohli, 2008). For instance, scholars choosing different methods and theoretical issues have drawn upon as diverse as phenomenology, symbolic interaction, 
hermeneutics, ethno-sociology, different variants of Marxism, Feminism and even structuralism (Atkinson, 2002; Bertaux \& Kohli, 2008; Sosulski, Buchanan, \& Donnell, 2010) which not only shows the diversity of its scope but opportunities it offers as a research method to the researchers hailing from various theoretical positions.

\section{Historical Roots of Life Story Work}

Life story research is not something new or unknown to the field of social sciences; instead, it is an old practice in the social sciences, while it has continued to have evolved throughout different time periods (Bertaux \& Kohli, 2008; Abu-Lughod, 1991), quite interestingly, other researchers have various point of views regarding the history and origins of life story or life history approach (Atkinson, 2002). The Polish Peasant in Europe and America, (published in 1958) by W.I. Thomas and Florian Znaneicki, is a classic and seminal work that showed its interest in the life story and explored the life experiences of polish migrants through detailed life history data collection (Bertaux \& Kohli, 2008).For example, Becker (2008) notes the close affinity between the two and argues how the sociology department at Chicago University encouraged the life history perspective vigorously during 1920 among the researchers in the field of city and city life as well as how it became fashionable and occupied a prominent place in the research schemes of the department (Becker, 2008:4).

Atkinson (2002) notes that Sigmund Freud's (1957) psychoanalytic method, in which he focused on individual case studies, might be the first genuine interest in the life history data, while Erik Erikson's (1975) use of life history also was concerned with the questions like how particular situations in an individual's life shapes her personality patterns. On the other hand, Charlotte Buehler (1968), utilizing the life history method to look at the human condition and the course of human life "identifies both maintenance and expressive features in the life course, such as creativity, consolidation, and adaptation" (p.96). However, life story has been different to different people, what has been at the heart of the life story research, is the concern with life, and a dedication to revealing it in various forms (Bertaux \& Kohli, 2008). 


\section{Life Story and Anthropology}

Atkinson (2002) argues that "the life history has long been a primary methodology of anthropological fieldwork (pp. 123)." Pointing out that anthropology has a long history of life story work, Bertaux and Kohli (2002) also argue that Oscar Lewis's and Sidney Mintz's work probably exerted relatively more significant influence on the life story work than The Polish Peasant (Mintz, 1960; Howell, 1983).Differentiating between life history and life story, Frank (1995) argues that under the influence of generic conventions and anthropology's traditional epistemological underpinnings of naturalism, the focus of the life history work remained mostly on diachronic change. On the other hand, life story research focuses on 'cultural scripts' and 'narrative devices' through which individuals make sense of their experience. Arguing that methodologically, life story research tends to be more phenomenological than life history, He (1995) continues that "Life story research emphasizes the truth of the telling versus telling the truth..." (p.145). However, Bertaux and Kohli (2002) lament that although anthropology's discipline has made quite significant contributions to the field of life story research, regrettably, it, though with few exceptions, has tended to move more towards 'scientism.' They consider this shift as a significant loss for the life story research.

Although, as a source of data collection, life history has been used in the social scientific research, roughly speaking, for about more than seventy years, but as Watson (1976) points out, “... it has nearly always occupied a marginal role in comparison to such techniques as structured observation, interviewing, and testing procedures whose purposes, generally, are experimentation and hypothesis testing (p.95)'. Frank (1995) points out the shift of interest in the individual life and lived experience in anthropological studies through the 1980s and 1990s, and thinks that along with many factors, "global transformation of poststructuralist order" also paved the way for a renewed interest in life stories.

\section{RESEARCH METHODOLOGY}

The use of narrative in phenomenologically inspired research has emphasized the importance of the narrative that "Humans live, remember and dream through stories. In an authentic sense, we domesticate this wild world of ours by narrative, making the flux and 
ambiguity of experience somehow comprehensible. Humans are storycreating animals. "Narrative is inescapable" (Reck, 1993:66).

The primary method of the data collection for this research was the life story approach of qualitative research methods. At the same time, the guided interview technique was employed to collect descriptions from the research participant. In contrast, the participant's identity has been kept confidential for better ethical research practices (Vanderstoep \& Johnston, 2009). Purposive sampling was followed to suit the theoretical requirements of the study. The male individual aged 31 belonged to the rural town of Tando Ghulam Ali, District Badin, Sindh. After building a good rapport with the participant, the life story interview was tape-recorded, transcribed, and then translated from the Sindhi language to English. The Interview was completed in an hour and consisted of anthropologists' dialogical approach (AbuLughod, 1991). The life story interview with the research participant was followed by a dialogue between the researcher and the participant to discuss the themes that emerged from the story and needed further understanding and elaborations. For data analysis, key themes were identified in the data and after thorough care and selection by using framework analysis approach to deal with the large volume of data garnered in the data collection process (Srivastava \& Thomson, 2009).

\section{RESEARCH OBJECTIVES}

This research's main objective was to understand personal, existential, temporal and affective aspects of participant's lived experiences; childhood, coming of age, present life circumstances and anticipations about time to come; that is, future. Therefore, this research contributes to this concern realized by anthropologists (AbuLughod, 1991; Jackson, 2005; Piette, 2014). Existential anthropology, pioneered by Michael Jackson (2005), has drawn upon existential and phenomenological thought to bring up new perspectives in anthropological domains that put existence at the center of any understanding of human beings. We explored the issues of meaningmaking inter-subjectivities, temporality, affectivity, and selfconsciousness among the research participants. They contributed to the age-old academic debate regarding individuality, agency, generalization, reductionism and determinism. 


\section{RESEARCH QUESTIONS}

Below are the questions that we addressed in the analysis of the experiential, emotive and temporal dynamics narrated by the research participant:

- How do young people live and make sense of their lifeworld socially and emotionally?

- Anthropology's hermeneutical school of thought has argued that meaning in life is fundamental. We seek to know how young people of small town engage in meaning-making?

- How do they construct the personal meaning of their lived experiences?

- We attempt to conceptualize research participants knowledge about the social structures, power, position, and social constraints which control their life events, life choices, and their effort to resist them?

\section{Life Story Interview of the Participant}

We had several informal meetings with the respondent sharing our research objectives and the technicalities of conducting life story interviews. Before conducting the interview, the participant would share some anecdotes from his life and whenever needed, he would ask how to initiate the interview, what should be included and what should be excluded. We established a friendly relationship with him that rested on mutual respect and trust, ensuring the research's ethical aspects. Before conducting the interview, he took time to reflect on his life and recollect his essential memories as he understands them. It worked because while we were listening to his life story, it looked like he had crafted his story with vivid details, sharp memories, emotions, meaning, and a recurring life theme that defined his life world as he continues to live.

He became very emotional while talking about his past life, especially his memories of leaving his hometown. His eyes became tearful while remembering those hard times when there was nothing to eat and times when he struggled to arrange the fees required to pay to the college. Though he was quite hesitant, his body language was confident and fluent as the interview proceeded and was getting more interesting. He would most of the time keep his eyes closed, which we think was good, as we believe he remembered and re-imagined the 
past events and memories to help him narrate them vividly. Below we present only a brief sketch of his life story. However, the discussion will be based on many anecdotes from the informal discussion, life story interview, post-interview dialogue, and participant observation.

The research participant was born and raised in a family that struggled to sustain itself in the face of limited resources. The family consisted of eleven people. Parents, five brothers, three sisters, and an uncle who lived with them. It was a large family but a very typical one in the rural areas of Sindh. He recalled that their only source of income was his father's services, who was an Aamil. An Aamil is somehow parallel to a Shaman. They are ubiquitous in Sindh. They are considered knowledgeable, who understand and resolve issues such as possession, black magic, evil eye, or jinn. People often visit them to seek their help and pay for some Nazrana or honorarium. But this little money was not sufficient for family members with increasing needs and demands. After taking into consideration their circumstances, they decided to open a shop of stamp vendor. To cover the expenses of furniture, they borrowed the loan from their relatives and friends. This allowed them to be relatively stable in at least fulfilling their basic needs. But the dream of going to school and getting proper education was still improbable for him. Although he narrated his life story, it looked like he never separated the story of his from that of his family. His story begins when he becomes young when he realizes his increasing needs, especially when he dreams of studying at university and reach somewhere. Working-class youngsters, especially youth from rural areas of Sindh, struggle for and see it as an only opportunity to break the shackles of want and impoverishment. But he was not only a dreamer, but he also wanted to make it happen, so he began working as an apprentice at a tailor shop, as he recounted, "After school, I would sew clothes that earned me around hundred rupees a day. Half of the money that I earned would be contributed towards the family's expenses, while the rest I would keep for my pens and books".

He continued to work part-time until matric. In the meanwhile, his family had also become self-sufficient, and their conditions improved gradually. Ultimately, he got admission to the college, but there were few and far worse problems his way this time around. He recalled, "I was so eager to go to college and attend the classes. 
However, because of the rural location of the college, where the concerned authorities generally enact little monitoring system, our classes would not take place as regularly as I wanted them to be." $\mathrm{He}$ could hardly have done this problem since it has been a prevalent issue among the schools and colleges in rural Sindh. The government and authorities have turned a blind eye and never ensured teaching and learning quality or regularity. The loss of education and prospects can be learned from his anecdote. Although his story's dominant theme is poverty and uncertainty, his resilience, persistence, and life goals, such as getting higher education, are critical. By viewing his family conditions as inevitable, he somehow understood them to be beyond his control. Yet, he weaved his selfhood in his narrative through the actions he took and his potential and will to act upon the circumstances in which he was born and raised.

\section{DISCUSSION}

Life themes that emerge from the life story include classconsciousness, displacement, self-consciousness about limits, embodied being, ambitions to achieve life goals, self-creation, and uncertainty. Below, we will discuss these themes one by one to better understand his life world as it is lived and made sense of and try to address answers to my questions that relate to self-understanding, selfidentity and meaning-making in youth.

\section{CLASS-CONSCIOUSNESS}

The themes of class consciousness were very dominant in his life story since childhood. He has not only lived an uncertain and troubled life but observed it in his family as well, which left quite a profound impact on his past life events, memories, and imaginations. For example, the times of uncertainty when they had nothing to eat at all, nor was there any proper source of income, shows that he was fully aware of their social position and the reason for their adverse conditions during his childhood.

He was a class-conscious person and was aware that family life and their social class background directly influenced his life as a kid when he said he was very interested in his studies and wanted to attend school. Still, because of the conditions of his family, he was not able to do so. The second time he mentions an event when he wanted to sit in 
the university's admission test, but this time again, according to him, he found money "a big hurdle in his way."

\section{SELF-CONSCIOUSNESS, LIMIT, AND EMBODIMENT}

The other theme that constitutes his life world is a strong selfawareness of his limits as embodied beings, who strive to surpass these limits by projecting himself on the conditions to make something out of it through self-realization. As a young guy who has experienced several constraints and limitations on his dreams of getting proper education and a possible living source, he has come to terms with it by being fully aware of the forces that he finds invincible. We are not talking about individual as free agent, rather we see it as an example of embodiment. We understand it to be the existential condition of human beings, a condition that informs the way human beings engage with themselves and the world of others.

In the same fashion, although he has been consciously engaged in the formation of selfhood and self-identify as an educated and sophisticated person, who has done graduation with dedication and hard work, he also realizes that he is unable to find a good source of income. He struggles to get admission to the university, the consequences of which are existentially and emotionally quite strong. For example, he says that "when I see other young guys of my age going to university, it makes me sad, it makes me cry. I envy their lifestyle, luxuries and being able to go to university. I wish I could also go to university." The emotive dimensions come to the fore here as he regrets and confesses that he cannot afford the university education and envious of other people who can go to university despite hard work and longing. The emotion of envy is evident in human beings and interestingly, since it is not considered a positive feeling; therefore, it is either shrouded or even not expressed.

In addition, it was encouraging to see him getting emotionally involved in the narration since it is the prerequisite of the life story interview that respondents keep in touch with his emotions and feelings so that the process of meaning-making could become possible.

\section{LIFE GOALS AND RESILIENCE}

It was interesting to listen to him speaking about his dreams and ambitions. He looked cognizant about his future objectives and the challenges he might face accomplishing them. Although, sometimes, 
we doubted them and they looked to us quite unrealistic, but it was amazing how he was still optimistic and ambitious about achieving his life goals. He wants to get admission to the university, which looks impossible to us given his financial circumstances for the time being. We knew he often runs short of money and hardly could survive a week outside his hometown. But he has his plans, and it looks like, for him, it is the project of self-creation; the process he is continuously engaged in. He told us that no one from his family has ever been able to do the graduation, except him, though.

The confidence and commitment to his life goals are evident when he said that "but, come what may, I believe I will make it to the university as well. I am ready to face any challenge. I will never give up; I will pursue my goals of education. I am confident that I can do this through hard work and resilience. Unless I am alive, I will keep educating myself." Keeping this into perspective, it seems that he has built a strong potential of resilience in himself throughout his life that poverty, setbacks, and challenge have characterized. This, in turn has enabled him to improvise certain strategies to cope with and stay firm in the face of adversity psychologically and emotionally.

Additionally, his capacity to improvise has allowed him to tackle any problem through social support and cooperation. As he himself points out, this is where he never hesitates to ask for help from people whenever he is in any trouble. He has built his social network which is always there for him to protect his stakes and interests. However, the main concern that defines his life goals is getting admission to the university and finding a proper livelihood. He considers education with high regard, as it entitles him a self-identity through which he engages with others vice versa.

\section{DISPLACEMENT}

Displacement puts life at risk since existence is uprooted by it and it never stays the way it was before it took place. It is regarded as unpleasant and even dangerous among human beings, as life is turned upside down because of it. The idea of place is socially and existentially crucial. Since it not only provides safety, but also a sense of belongingness and identity rooted in memories, both collective and personal. He had spent most of his childhood in a village, but they had to migrate to another town, hoping for a better livelihood source. Although he did not talk about his childhood positively, this 
displacement had impacted him psychologically and existentially. Leaving one's house, village, friends, and land where one once lived and played is disturbing and painful. When we asked him about his feelings when they left their home and hometown, he was very emotional and perhaps sad while telling the story: "It was quite hard. We still remember that house. It was our paternal house. Whenever we remember that house, it makes us cry. We spent our childhood there. It was situated in an open environment in a typical rural area. We believe it was good for us, but lack of a livelihood forced us to migrate here."

Largely, having experienced displacement and poverty in early childhood must have been very grave in adjusting to a new environment. That is why he was also nostalgic about their prior home from where they migrated.

\section{UNCERTAINTY}

Despite having a clear understanding of his key life events, transitions in his life, ambitions of future life goals and being selfaware of his potential to respond to the challenges ahead of him, his present life looks highly uncertain as he expressed it himself: "For the time being, my present life, I would like to clarify, is quite bitter.... Because once a child gets matured, his needs increase significantly. Many of the needs cannot be met. I am an educated guy. There are no chances of a job as well'". He was very upset and disappointed about his life as he lives a life that is not satisfying to him. As we have observed, past life, which was quite unkind to him, in terms of his ideal schooling and coming of age, had made him experience displacement and poverty, while the present life is also uncertain when it comes to his goals of studies and lack of employment. We think this is where we find our answers.

First, it appears that his life world has been characterized by disruptions such as displacement, poverty, hunger, inability to support his studies and to find a suitable source of income. He can hardly meet his needs as he points out himself about his present life circumstances. This is a typical example of young people's uncertain life in changing rural areas of Sindh with increased needs yet unable to sustain them because of dysfunctional families, class structures, and general lack of orientation needed in contemporary society. He looked emotionally disturbed with this painful condition of him being so poor that it has affected him enormously. He makes sense of his life world as unstable 
and vulnerable, while on the other hand, he has goals and a specific orientation towards a future that is quite dependent on present conditions.

Secondly, his stance toward his life in its temporal mode has been like an outside observer who breaks down every element and dimension to understand the phenomenon better. Human beings' emotive and affective facet also reveals itself while narrating life in a constant flux of ambiguity and uncertainty.

In addition, the emotive dimension is shown in his life story also reveals that the possibility of any existential meaning of being and life emerges when emotions and feelings come into play rather than any attempt to rationalize any issue under consideration. Thirdly, we can learn what it means for any person to be at all? This question pertains to the human condition. We have narrowed it down to only one person of this town who engages in self-understanding, relatedness, coexistence, and inter-subjectivity. It brings insights into this area's human condition and what kind of life they lead throughout different life stages and certain meanings and orientations.

The most important answer from this life story is that the respondent was able to know his situatedness; that is to say, he was fully aware of how the world of others worked, his relationship with them, and his place he held in that world. He was well aware of the hindrances and forces that were on his way to act independently. The events were just beyond his control. For example, he needed good support to get him where he wants himself to be because he struggled to meet his needs.

Notwithstanding that he is living an uncertain life, the qualities of resilience, commitment, and ambitiousness are what it be means to human.

\section{CONCLUSION}

This research's main objective was to explore young people's life world to understand hermeneutical, temporal, emotive, and experiential dynamics of being-in-the-world. The questions surrounding self-consciousness and meaning-making of lived experiences were also addressed in the research on the epistemological level. It is argued that the tendencies of hypostatization and reduction of human existence can be problematized and dealt with in 
anthropological theory that constitutes the questions in our field of inquiry.

While, on the theoretical level, disappointed with the conventional concern of anthropology with culture and society, which tends to reduce, generalize and compartmentalize human being into what Heidegger called "ontic categories" along with glassing over the issues of individual diversity, selfhood, ontology, and existential dynamics of being, this research was, thus, inspired by phenomenology and existentialism. It built up its theoretical underpinnings on the ideas of existentialist philosopher Martin Heidegger (1889-1976) and as further elaborated by the pioneers of the field of existential anthropology Michael Jackson (2005) and Albert Piette (2014). Whereas, methodologically speaking, the life story interview method was experimented with existential anthropology. Life story interview, therefore, were used as a source of garnering description from research participant. It not only looked like a natural manner of "speaking about oneself" but helped participant fully express himself and share lived experiences without being restricted to specific topics. Additionally, as a researcher, it allowed us to access these experiences and meanings made by participant about them. Thus, it is argued that this is an excellent method that can be used in conjunction with research themes that fall in the domain of existential anthropology. It was learned that the participant knew that he needed to be in a special kind of state of mind or mood to be reflective and introspective about his life. If this was not happening, we had to try to induce him into a retrospective mood so that deeper meanings can be brought up.

We argue that the meaning-making of lived experiences was different among youth of the same area. However, they made sense of their life-world with a strong presence of selfhood and selfconsciousness in temporal and affective fashion. Participant was more insightful and perceptive regarding life in connection to the past because of uncertain present life circumstances. Secondly, he experienced self-transformation at different moments and times of life; thus, they were also accompanied by meaning-making, such as why and how they were experienced and felt like when different mode of existence came through. Thirdly, he was very well attuned with his life world vis-à-vis the world of others and aware of his position in social 
and hierarchical order. He was also aware of the limits and potentialities and pointed out how certain unavoidable events controlled his life. This issue touched upon the being's awareness of its situatedness and embodiment as an existential condition for beingin-the-world.

Interestingly, although scholars criticize a linear understanding of time, it was observed that there was a strong awareness of the past as a starting point and a tendency to conceptualize time in nearly chronological order, that is, past, present, and future. There was confident readiness among the participant that past events had a direct connection with the present condition of life. Nevertheless, the orientation towards these time periods of life was significantly different among the young people of this town and much different from other places of the world. For example, we cannot help myself by giving an example of a participant who did not have any particular anticipations and preparations about the future.

This research went beyond the horizons of culture and society to put existence, life, and being, which are silhouetted at meta-level, at the heart of anthropological focus. This research has contributed to the growing area of interest of Phenomenology, Existential anthropology and potential methodology. They can be complemented with the rigor of ethnography and reflexivity to understand issues such as selfhood, lifeworld, life course and meaning making, among others.

\section{REFERENCES}

Abu-Lughod, L. (1991). Writing against Culture. In R. G. Fox, Recapturing Anthropology: Working in the Present (pp.137-162). School of American Research Press.

Atkinson, R. (2002). The Life Story Interview. London: Sage Publications.

Becker, H. (2008). The Life History and the Scientific Mosaic. (B. Harrison, Ed.) Life Story Research, I, 3-13.

Bertaux, D., \& Kohli, M. (2008). The Life Story Approach: A continental View. (B. Harrison, Ed.) Sage Publications in Social Research Methods, 1.

Desjarlais, R., \& Throop, C. J. (2011). Phenomenological Approaches in Anthropology. Annual Review of Anthropology, 40(1), 87-102. Retrieved 3 8, 2021, from https://annualreviews.org/doi/abs/10.1146/annurev-anthro$\underline{092010-153345}$

Dyring, R. (2012, 11 21). Existential Anthropology. Retrieved April 20, 2015, from Aarhus Universitet: http://projects.au.dk/existential-anthropology

Frank, G. (1979). Finding the Common Denominator: A Phenomenological Critique of Life History Method. Ethos, 7(1), 68-94. 
Frank, G. (1995). Anthropology and Individual Lives: The Story of the Life History and the History of Life Story. American Anthropologist, 97(01), 145-48.

Friedl, E. (1994). Lila Abu-Lughod, Writing Women's Worlds: Bedouin Stories (Berkeley: University of California Press, 1992). Pp. 289. International Journal of Middle East Studies, 26(02), 309-311. Retrieved 3 8, 2021, from https://cambridge.org/core/journals/international-journal-of-middleeast-studies/article/abulughodlila-writing-womens-worlds-bedouin-storiesberkeley-university-of-california-press-1992-pp289/629c905c1ceb75eee1f58d2efd25f0e7

Hahn, C. J. (2012). The Concept of Personhood in the Phenomenology of Edmund Husserl. Retrieved 3 8, 2021, from https://epublications.marquette.edu/cgi/viewcontent.cgi?article=1192\&con text=dissertations $\mathrm{mu}$

Howell, N. (1983). Nisa: The Life and Words of a !Kung Woman. MARJORIE SHOSTAK. American Ethnologist, 10(1), 187-188. Retrieved 11 19, 2020, from https://anthrosource.onlinelibrary.wiley.com/doi/pdf/10.1525/ae. 1983.10.1.02a00230

Jackson, M. (2005). Existential Anthropology: Events, Exigencies and Effects. New York: Berghahn Books.

Jackson, M. (2013). Lifeworld Essays in Existential Anthropology. Chicago and London: The University of Chicago Press.

Jackson, M., \&Piette, A. (2015). What is Existential Anthropology. New York and Oxford: Berghahn Books.

James, C., \& Marcus, G. E. (1986). Writing Culture, The Poetics and Politics of Ethnography. Berkeley: University of California Press.

Leys, C. (1976). The 'overdeveloped' post colonial state: a re-evaluation. Review of African Political Economy, 3(5), 39-48. Retrieved 3 8, 2021, from https://tandfonline.com/doi/abs/10.1080/03056248108703276

Mintz, S. (1960). Worker in the Cane: A Puerto Rican Life History. Yale University Press. Retrieved 11 19, 2020

Morsy, S. A. (1995). Writing Women's Worlds: Bedouin Stories. LILA ABU-LUGHOD. American Ethnologist, 22(2), 424-425. Retrieved 3 8, 2021, from https://anthrosource.onlinelibrary.wiley.com/doi/pdf/10.1525/ ae.1995.22.2.02a00200

Piette, A. (2014). Existential anthropology: what could it be? an interpretation of Heidegger (Vol. 4). Argument: Biannual Philosophical Journal.

Rahman, T. (n.d.). The Class Structure of Pakistan. OUP Pakistan. Retrieved 3 8, 2021, from https://books.google.com/books?id=Z1WkMQEACAAJ

Rapport, N., \& Overing, J. (2000). Social and Cultural Anthropology: The Key Concepts. London: Routledge.

Reck, G. G. (1993). Narrative and Social Science: Reclaiming the Existential. Issues in Integrative Studies (11), 63-74. 
Siddiqa, A., \& Siddiqa-Agha, A. (2007). Military Inc: inside Pakistan's military economy. Pluto Press. Retrieved 3 8, 2021, from https:// books.google.com/?id=E9jeAAAAMAAJ

Sosulski, M. R., Buchanan, N. T., \& Donnell, C. M. (2010). Life History and Narrative Analysis: Feminist Methodologies Contextualizing Black Women's Experiences with Severe Mental Illness. Journal of Sociology \& Social Welfare, XXXVII (3), 30-57.

Srivastava, A., \& Thomson, S. B. (2009). Framework Analysis: A Qualitative Methodology for Applied Policy Research. Retrieved 11 19, 2020, from http://research.apc.org/images/a/ad/framework analysis.pdf

Stocking, G. W. (1990). Malinowski's Diary and a Humanistic Anthropology. Agricultural History, 15(4), 110-110. Retrieved 11 13, 2020, from http://onlinelibrary.wiley.com/doi/10.1525/ahu.1990.15.4.110/abstract

Teitz, U. (2006). German Existence-Philosophy. In H. L. Dreyfus, \& M. A. Wrathall, A companion to Phenomenology and Existentialism (pp. 162187). Oxford: Blackwell Publishing Ltd.

Vanderstoep, S. W., \& Johnston, D. D. (2009). Research methods for everyday life blending qualitative and quantitative approaches. San Francisco: Jossey-Bass.

Watson, L. C. (1976). Understanding a Life History as a Subjective Document: Hermeneutical and Phenomenological Perspectives. Ethos, 4(1), 95-131.

Weiner, J. F. (2001). Tree Leaf Talk A Heideggerian Anthropology. Oxford: Berg. 